Jurnal Keperawatan Padjadjaran

ISSN 2338-5324 (print)

ISSN 2442-7276 (online)

Online di http://jkp.fkep.unpad.ac.id

DOI : $10.24198 / \mathrm{jkp}$

\title{
Effectiveness Blended Learning in Reducing HIV-related Stigma and Discrimination among Nurses: A Queasy Experimental Design
}

\author{
Heni Purnama ${ }^{1}$, Nyayu Nina Putri Calisanie ${ }^{1}$, Linlin Lindayani ${ }^{1}$, Taryudi Taryudi ${ }^{2}$ \\ ${ }^{1}$ West Java Indonesian Nurses Association's School of Health Science, Bandung, Indonesia \\ ${ }^{2}$ Universitas Negeri Jakarta, Tangerang, Indonesia \\ Corresponding Email: linlinlindayani@gmail.com
}

Submitted: 10-09-2020 Accepted: 05-11-2020 Published: 01-12-2020

\begin{abstract}
Scale-up of stigma-reduction programs in healthcare settings has been slow in part due to lack of understanding and social norm associated with pre-existing stigma in HIV population. The application of blended learning can bridge the gap between theory and practice and make the learning experience more meaningful so that it can be applied as a way of learning to reduce stigma against PLWHA from healthcare professional. The aimed of this study was to determine the effectiveness of blended learning in reducing the stigma of nurses toward people with HIV/AIDS (PLWHA). This study used a quasi-experimental pre-post-test design with two groups (the intervention group and the control group). The samples in this study were nurses who worked at the public health center in Bandung. HIV-related stigma and discrimination (S\&D) questionnaire was used to measure HIV-related stigma among nurses. Mean, standard deviation, frequency was used to explain demographic data and main variables. In the intervention (blended learning) group, there was a significant different of the mean score of HIV-related S\&D before and after blended learning intervention with $\Delta$ mean was 4.37 and $(p=0.001)$. In the control group, there was no significant different of those $\Delta$ mean was $3.39(p=0.459)$. A significant difference found in the post test mean score of HIV-related stigma and discrimination between intervention and control group $[\mathrm{F}=569.018$, $(\mathrm{p}=0.000)]$. This study found that blended learning could reduce the HIV-related stigma and discrimination from nurses. This underscores the utility of this intervention to change the perceived of stigma and discrimination of health workers, as well as potential to generalize or adapt this intervention to other settings in the region and beyond.
\end{abstract}

Keywords: Blended learning, discrimination, HIV-related stigma, intervention, nurses.

Volume 8 Issue 3 December 2020 
Heni Purnama: Effectiveness Blended Learning in Reducing HIV-Related Stigma and Discrimination

\section{Introduction}

The total cases of HIV/AIDS in Indonesia as of June 2018 were 301,959 people and most commonly found in the productive age group, which is spread over $433(84.2 \%)$ of 514 districts or cities in 34 provinces (RahmatiNajarkolaei et al., 2010). A previous study revealed that most of the PLWHA were aged between $20-29$ years old $(66.2 \%)$, and $79.2 \%$ of they are still working (Ibrahim et al. 2017). The challenge in combating HIV/AIDS is reducing the stigma and discrimination experienced by people living with HIV/AIDS (PLWHA). The facts show that due to this problem, PLWHA has kept the HIV status hidden from family members for many years (Yiu et al., 2010). This condition potentially cause PLWHA to not get access to optimal health, services and treatment, thereby increasing the risk of complications from the disease they suffer (Rahmati-Najarkolaei et al., 2010; Lindayani \& Maryam, 2017). PLWHA experiences stigma when first diagnosed because it is related to a lack of knowledge about their disease, this status will last for 6 months and increase for 15 years (Kurien et al., 2007).

Stigma is multidimensional constructs and reinforced by social disparity, thus deeply discrediting people and reducing their status in society (Erving Goffman, 1963). Stigma is when someone see you in negative ways, while discrimination is someone treat you in negative ways (Kinsler et al., 2007). The prevalence of stigma against PLWHA by health workers was reported to be quite high at $15.4 \%$ (Dlamini et al., 2009). This stigma occurs in the form of not receiving health services because of their status, movement from one officer to another, not getting proper care, being mistreated by nurses or other health workers (Banteyerga et al., 2005). Scale-up of stigma-reduction programs in healthcare settings has been slow in part due to lack of understanding and social norm associated with pre-existing stigma in HIV population. As HIV is closely associated with pre-exiting stigmatized groups, such as homosexuals, injecting drug users, and commercial sex workers, which have always been taboo topics among Indonesians, it is not surprising that all this has led to stigmatizing the disease all the more (Lindayani et al, 2017). Various attempts have been made to reduce stigma, namely HIV services, provision of information about HIV, education and counseling (Yiu et al., 2010). However, due to unequal understanding of HIV/AIDS, the stigma rate remains high. Perceptions of irrational fear of HIV transmission are a factor in the emergence of stigma among health workers in Indonesia (Feyissa et al., 2012).

The training obtained by health workers and good knowledge does not have a direct effect on the stigma of health workers towards PLWHA(Musheke et al., 2013). This may due to the majority of previous training was lack of theoretical guideline for behaviors change and may cause boring due to conventional methods. Although this technique is well received and has demonstrated promising results, time and the capacity to scale up timeintensive projects are two main challenges in a busy health delivery system. Ideally, all workers in a facility will undergo in-person, participatory stigma-reduction training addressing all the primary drivers of stigma as a common practice, from workers to medical professionals. In fact, most health facilities will struggle to find the time to give all their workers this form of training. The results of this study indicate that a specific strategy is needed based on social cognitive theory by combining interpersonal interactions and interventions to achieve behavior change in reducing stigma against PLWHA (UNAIDS, 2016).

Blended learning is an effective learning method by combining various combinations of teaching methods, methods and models (Manganye et al., 2013). Previous study indicated that through blended learning, participant were have flexible time, not cause boring due to do not stand by whole day in room, and have changeling to operate available information technology (Manganye et al., 2013). The study reported a positive response and satisfaction from the application of blended learning that was felt by both teachers and subjects (Nyblade et al., 2009; Sweeney \& Vanable, 2016). The application of the blended-learning method has been shown to significantly influence behavior change (Li et al., 2013; Steward et al., 2013). 
The application of blended learning can bridge the gap between theory and practice and make the learning experience more meaningful so that it can be applied as a way of learning to reduce stigma against PLWHA
(Nyblade et al., 2009). Therefore, this study aimed to determine the effectiveness of blended learning in reducing the stigma of health workers in people with HIV/AIDS (PLWHA).

\section{Conceptual framework}

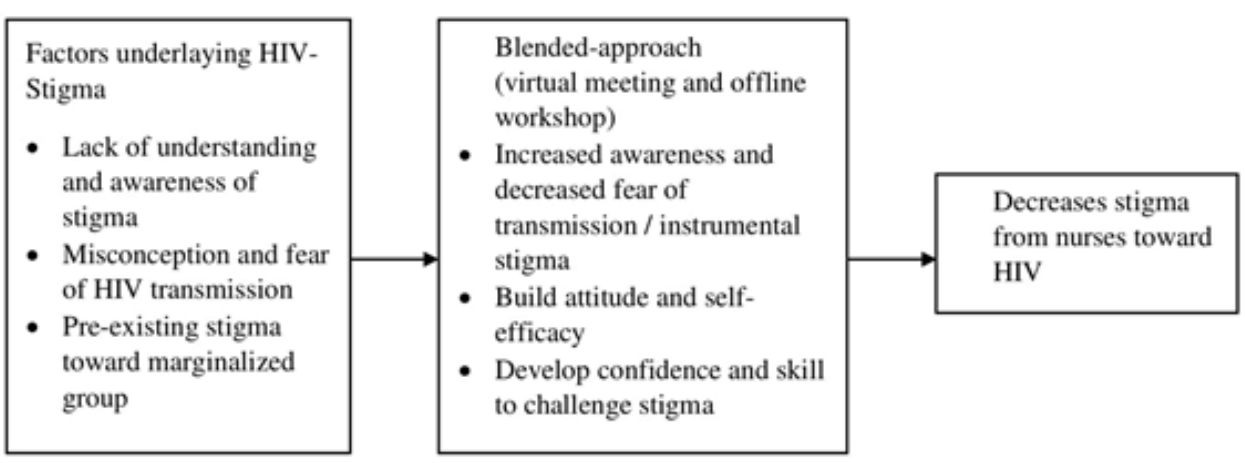

Figure 1 Conceptual Framework

The intervention used in this study refers to a behavior change strategy. Behavior change strategies are based on the principles of social cognitive theory which emphasize the importance of combining interpersonal interactions with specific strategies that promote behavior change(Bandura \& Walters, 1977). This can include the establishment of safe spaces for contact between stigmatized and stigmatized offenders (contact strategies) who seek to break down discrepancies and promote empathy (Nyblade et al, 2018). It may also involve observational learning and the function of feedback to encourage selfefficacy. This method includes observational learning and role-playing with feedback to increase self-efficacy (Nyblade et al, 2018). Thus, such activities as computer-based selftesting, skills training for interacting with PLHIV, interactive games, and presentations by people living with HIV are designed to educate, promote learning, reduce distance and "us vs. them," create empathy and build self-efficacy. These strategies are then used to develop activities to address fears and misconceptions around HIV transmission (e.g., "instrumental stigma"); negative attitudes towards people living with HIV and marginalized groups vulnerable to HIV infection (e.g., "symbolic stigma"); and a lack of awareness of stigma and its effects
(Nyblade et al, 2018).

\section{Method}

This study used a quasi-experimental pre-post-test design with two groups (the intervention group and the control group) which aimed to determine the effectiveness of blended learning in reducing the stigma of health workers in people with HIV/AIDS (PLWHA). This study was approved by ethical committee of affiliated university (III/012/KEPK/STIKep/PPNI/Jabar/2020) prior to data collection.

The intervention has been conducted for 3 months, including 1-month preparation stage (phase I and II) and two months intervention. Participant in intervention group received eight-week workshop session consisting virtual workshop and offline workshop. Each week has different learning objective lead by HIV expert including nurse practitioners and academicians. Control group were only receiving an information related to new evidence in HIV prevention and treatment through leaflet.

The intervention was consisting of 3 phases. Phase 1: researchers tried to identify readiness and understanding and service schedule, review of existing training modules, 
and identify existing content to be adopted in the module. Module is consisting of general information and new evidence regarding HIV and stigma reduction program that focus on concretely learn what stigma is and what its consequences are (i.e., how stigma fuels the HIV epidemic). The content of module was validated using a content analysis reviewed by 5 experts using a standard form (consist of content each chapter) to check each content appropriateness, relevancy, accuracy and readability. Phase II: develop scripts for each training session with input from health behaviors, 2 nurse practitioners in infection control, 2 nursing academicians that have more than 2 publication in HIV-related stigma review, 1 PLWH. They were asked to review the scrip and revise training scenarios, creating visual content from the drafted scenario: site identification, filming, editing, and visual education production. Phase III: pilot testing: test content and data for each intervention session; pilot testing is carried out on nursing students, and revision and finalization of intervention protocols. Pilot training has been performed for two months (8-week workshop session, once a week), and each session has been set up for 60 minutes. Below is a chart of the intervention flow (Figure 2).

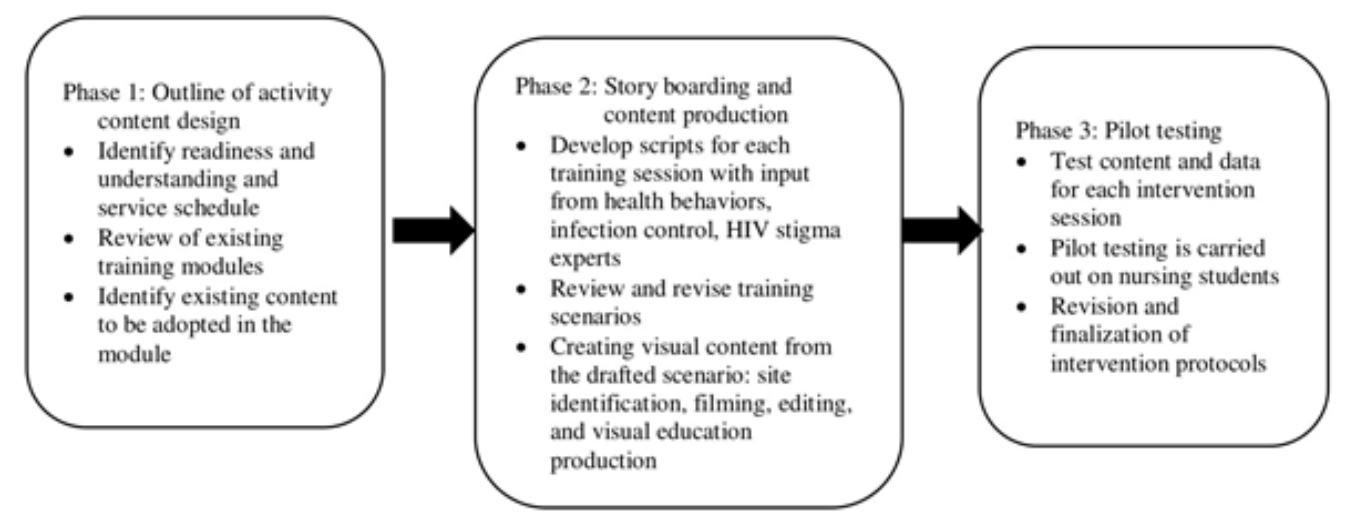

Figure 2 Intervention procedures adopted from Nyblade et al. (2018)

From this pilot testing, we developed a final protocol of this study. Each week consisted of:

1. First-second week virtual workshop (sensitivity and fear of transmission / instrumental stigma): emphasis on finding and resolving information gaps in HIV transmission, on how to mitigate specific risk when providing services (standard precautions) and on recognizing the value of systematic implementation of standard precautions. This session focuses on answering specific concerns that participants may have about casual contact with HIV-positive patients, as well as more general myths and assumptions about HIV transmission and linkages, and acknowledges that health workers face real risks of HIV transmission in the course of their work, e.g., from needle sticks.

2. Third-fifth week offline workshop
(Attitudes (Symbolic Stigma): Activities aimed at helping trainees understand stigmatizing attitudes and how they can affect the level of care given, often in unrecognized ways. Such behaviors can be conveyed, for example, through verbal and body language, by embarrassment, remorse, and judgment, as well as through other discriminatory practices such as making such patients wait to be seen last, even though they have arrived earlier than others.

3. Six-eight week offline and online workshop (recognition and internalization): Emphasis on video of stigma faced by a person living with HIV in a household environment, selfreflection exercise asking participants to recognize and consider a time in their lives, three video testimonials of people living with HIV with self-reflection questions to create empathy and minimize blame.

The populations in this study were all 
nurses who worked at 5 public health centers in Bandung with approximately around 125 nurses in total excluding those who take leave for any reason. Health services for PLHIV in Bandung City refer to the One Stop Service system where patients get access to integrated health services at the same location and time at health care facilities.

The inclusion criteria in this study were: all health workers who were willing to participate in the research. The sample technique used is convenience sampling. The number of samples was calculated using G-Power Software Version 3.1.6 assuming the $\mathrm{t}$ test, $\alpha=0.05$, effect size $=0.60$, power level $=0.80$. To anticipated drop out, we add $30 \%$ of sample from total estimation. So that the total samples to be recruited 94. In final data collection, there were 100 participants joined in this study.

HIV-related stigma and discrimination (S\&D) questionnaire was used to measureHIVrelated stigma from healthcare professionals. This questionnaire was deliberately designed to capture immediately stigma drivers and enacted stigma. Eighteen core questions measure three programmatically actionable drivers of stigma within health facilities (worry about HIV transmission, attitudes towards people living with HIV (PLHIV), and health facility environment, including policies), and enacted stigma. This instrument consists of 3 options $(0=$ disagree/do not known, $1=$ agree) for health facility policies and work environment, and two options (worried/not worried) for worry related to contracting HIV when caring or providing services to people living with HIV. Then for option about people living with HIV and observed stigma, infection precaution measure, and experience of secondary stigma, the answer consists of $0=$ disagree $/$ do not known, 1 = agree). The questionnaire also includes one short scale for attitudes towards PLHIV (5-item scale, $\mathrm{a}=0.78$ ). Permission to use the instrument was obtained from Health Policy Project, USA and it's free to use. This instrument has been translated into Indonesian using forward translation by one people from major health background have knowledgeable of English-speaking culture but his/her mother tongue should be the primary language of the target culture and backward translation by an independent translator, whose mother tongue is English and have no knowledge about questionnaire. The item-correlations was check using person correlation with the $r$ value ranged from 0.45 to 0.61 , while cronbach Alpha in the current study was 0.798 .

We conducted a test of normal duration distribution. The results or normality testing showed that data was normally distributed based on the no significant KolmogorovSmirnov test, Mean, standard deviation, and frequency was used to explain demographic data and main variables. Differences in baseline characteristics between the intervention and control groups will be tested using an independent t-test. The difference in results between the two groups after intervention, we will use the ANCOVA test. The data will be analyzed using SPSS version 22 for windows. A significance level of $5 \%$ will be used for comparisons between intervention and control group.

\section{Results}

Table 1 Demographic characteristic of studied participants

\begin{tabular}{lccc}
\hline \multicolumn{1}{c}{ Characteristics } & $\begin{array}{c}\text { Intervention Group } \\
\mathbf{n = 5 0 , ( \% )}\end{array}$ & $\begin{array}{c}\text { Control group } \\
\mathbf{n = 5 0 , ( \% )}\end{array}$ & p-value \\
\hline Age in year (Mean \pm SD) & $24.95 \pm 9.37$ & $25.26 \pm 9.04$ & $0.077 \mathrm{a}$ \\
Gender & $9(18)$ & $11(22)$ & $0.179 \mathrm{~b}$ \\
Male & $41(82)$ & $39(78)$ & \\
Female & & & \\
Marital Status & $30(60)$ & $35(70)$ & $0.089^{\mathrm{b}}$ \\
Married & $20(40)$ & $15(30)$ & \\
Single & & & \\
Working status & & &
\end{tabular}


Heni Purnama: Effectiveness Blended Learning in Reducing HIV-Related Stigma and Discrimination

$\begin{array}{lccc}\text { Permanent } & 38(76) & 40(80) & 0.674^{\mathrm{b}} \\ \text { Temporary /Contract } & 12(24) & 10(20) & 0.372^{\mathrm{a}} \\ \text { Working experience } & 4.95 \pm 1.37 & 5.26 \pm 1.04 & \\ \begin{array}{l}\text { Ever received HIV } \\ \text { training }\end{array} & & & 0.456^{\mathrm{b}} \\ \text { Yes } & 12(24) & 14(28) & \\ \text { No } & 38(76) & 36(72) & \end{array}$

Note: ${ }^{\mathrm{a}}$ independent $\mathrm{t}$ test, ${ }^{b} \mathrm{Chi}$ square.

Table 2 HIV-related stigma and discrimination (S\&D) before and after intervention in the blended learning group $(n=50)$

\begin{tabular}{|c|c|c|c|c|c|c|c|}
\hline & \multicolumn{2}{|c|}{ Pre-test } & \multicolumn{2}{|c|}{ Post-test } & \multirow{2}{*}{$\frac{\Delta}{\text { Mean }}$} & \multirow{2}{*}{$\mathbf{t}$} & \multirow{2}{*}{ p-value } \\
\hline & Mean & SD & Mean & SD & & & \\
\hline $\begin{array}{l}\text { HIV-related } \\
\text { S\& D }\end{array}$ & 24.49 & 6.65 & 20.12 & 3.34 & 4.37 & 10.19 & 0.001 \\
\hline $\begin{array}{l}\text { Drivers (18 } \\
\text { items) }\end{array}$ & 16.44 & 3.53 & 12.85 & 2.84 & 3.59 & 7.95 & 0.001 \\
\hline $\begin{array}{l}\text { Enact } \\
\text { Stigma (9 } \\
\text { items) }\end{array}$ & 6.98 & 2.34 & 4.15 & 1.61 & 2.84 & 6.87 & 0.001 \\
\hline
\end{tabular}

Table 3 HIV-related stigma and discrimination (S\&D) before and after intervention in the control group $(\mathbf{n}=\mathbf{5 0})$

\begin{tabular}{lccccccc}
\hline & \multicolumn{2}{c}{ Pre-test } & \multicolumn{2}{c}{ Post-test } & \multicolumn{1}{c}{$\Delta$} & \multirow{2}{*}{ t } & \multirow{2}{*}{ p-value } \\
\cline { 2 - 6 } & Mean & SD & Mean & SD & Mean & & \\
\hline $\begin{array}{l}\text { HIV-related } \\
\text { S\& D }\end{array}$ & 20.49 & 6.65 & 19.12 & 7.34 & 1.37 & 3.99 & 0.459 \\
Drivers & 13.44 & 3.53 & 11.85 & 2.84 & 1.59 & 1.59 & 0.438 \\
Enact & 4.15 & 1.34 & 4.11 & 1.61 & 0.04 & 1.13 & 0.677 \\
Stigma & & & & & & & \\
\hline
\end{tabular}

Table 4 Differences of HIV-related stigma and discrimination between two groups $(\mathbf{n}=100)$

\begin{tabular}{lccccc}
\hline \multicolumn{1}{c}{ Source } & $\begin{array}{c}\text { Type III sum of } \\
\text { square }\end{array}$ & Df & Mean Square & F & p-value \\
\hline Corrected model & 1321.02 & 2 & 412.013 & 170.021 & 0.000 \\
Intercept & 1512.020 & 1 & 1512.020 & 470.081 & 0.000 \\
Pre-test & 219.027 & 1 & 219.027 & 70.075 & 0.000 \\
Group & 1830.102 & 1 & 1830.102 & 569.018 & 0.000 \\
Error & 7200.12 & 167 & 5.139 & & \\
Total & 111199.001 & 170 & & & \\
Corrected total & 2822.291 & 168 & & & \\
\hline
\end{tabular}


Of 100 participants joined in this study, 50 in the intervention group and 50 in control group. The majority of respondents were female ( $82 \%$ in intervention group and $78 \%$ in control group), married $(60 \%)$, permanent worker $(76 \%)$. The average age of respondents in the intervention group is $24.95+9.37$ years. The average age of respondents in the control group was $25.26+9.04$ years. The mean of working experience was There were 4.95 $(\mathrm{SD}=1.37)$ in intervention group and 5.26 $(\mathrm{SD}=1.04)$ in the control group. There were no significant differences of age distribution, gender, marital status, working status, working experience, and ever received HIV training between intervention and control groups ( $p>0.05)$ (Table 1).

Table 2 shows HIV-related stigma and discrimination (S\&D) before and after intervention in the blended learning group. There was a significant different of the mean score of HIV-related S\&D before and after blended learning intervention in the intervention group ( $\Delta$ mean 4.37 and $p=$ 0.001 ). In addition, the driver's stigma and enact stigma also decreased after intervention $(\Delta$ mean $=3.59 ; \mathrm{p}=0.001$, and $2.84, \mathrm{p}=0.001$, respectively).

Table 3 shows HIV-related stigma and discrimination (S\&D) before and after intervention in the control group. There was no significant different of the mean score of HIV-related S\& before and after blended learning intervention with $\Delta$ mean was 3.39 and $p=$ value was 0.459 . In addition, driver's stigma and enact stigma was no decreased with $\Delta$ mean was 1.59 and 1.13 , respectively ( $p$-value $>0.05)$.

ANCOVA result in Table 4 reveals that there was a significant difference in the mean score of post-test HIV-related stigma and discrimination between blended learning group and control group [F=569.018, $\mathrm{p}$-value $(0.000<0.05)]$. The null hypothesis is therefore rejected. This implies that between blended learning is significantly more effective than discussion method in improving HIV-related stigma and discrimination.

\section{Discussion}

This study found that blended learning could reduce the HIV-related stigma and discrimination from nurses. Previous research conducted in America tried to develop blended learning using a mobile-App that adopted the principles of social cognitive theory Bandura \& Walters (1977) which emphasized the importance of combining interpersonal interactions with specific strategies that encourage behavior change. This can include creating safe spaces for contact between stigmatized and stigmatized actors (contact strategies), which serve to break down differences and cultivate empathy (Chan \& Tsai, 2017; Pettigrew \& Tropp, 2006; Batson et al., 2003; McKeever, 2015). In this study, blended-learning approach was specifically designed to address the busy time constraints of healthcare professionals, it is noteworthy that scheduling and time availability remained a challenge for ward staff working in the hospital even at three relatively brief sessions. These strategies are then used to develop activities to address key actionable drivers of stigma: fear and misconceptions surrounding HIV transmission (i.e., "instrumental stigma"); negative attitudes toward people living with HIV and marginalized groups who are vulnerable to HIV infection (i.e., "symbolic stigma") and a lack of awareness of stigma and its impacts. Future study using rigor method is needed to confirm this finding.

The importance of solving HIV stigma in health care facilities in order to improve quality of care and patient achievement is well recorded and accepted (Pisal et al., 2007; Yiu et al., 2010). What is less well understood is how to effectively reduce that stigma for participation in training or other learning activities within the confines of an extremely busy health delivery system and limited staff time at the health facility. The study-designed three-session intervention offers a possible solution to this challenge, combining two self-directed, tablet-administered learning sessions with one in-person group session. While it will be sometime before the trial is finished and the results are known, feedback from the experience of early implementation suggests such an approach is feasible and well received by nurses. Most participants took part in the sessions and gave constructive reactions through statement on the training 
Heni Purnama: Effectiveness Blended Learning in Reducing HIV-Related Stigma and Discrimination

and learning process. Since there was a time gap between completing the tablet sessions and group sessions, the intervention coordinator noted that several participants told the facilitators that when the videos were completed (tablet sessions), they changed their behavior towards clients living with HIV because "they removed that fear from our mind."

Most crucial is the lesson that people with lived HIV and stigma experience must be central to designing and delivering HIV-stigma reduction treatments. People living with HIV provided input into the development of the script and took part in the videos depicting the roles of people living with HIV. The inperson group session is about having a person living with HIV present to share experiences with participants and interact with them. Experience to date indicates this is the most important single interaction for participants in the intervention. Typically, it's the first time they interact with an openly positive person living with HIV outside of a health facility or patient / provider environment. As has been shown in reducing mental health stigma, contact between stigmatization and stigmatization is central to effective reduction of stigma (Corrigan et al., 2012). It should also be mentioned that since the contents for this intervention were designed, the mHealth sector has made significant progress. Hence, the range of options provided by HIV-Stigma Reduction for Health-Facility staff providing the self-directed learning component is increasing rapidly. For example, the intervention's tablet session could now be delivered on a smartphone, tablet device or in the ward via a computer terminal with cloud access to content or a learning management system.

Overall, the approach does have some limitations. This curriculum is established to identify individual level of stigma bot included institution level. It will be important to intervene at both this individual and broader institutional level to create sustainable change across a health care system. This study conducted using queasy experimental without control group which not counted the true effect of the program. Second, the sample size was smaller that would be resulting less sensitivity to detect power or magnitude for the effect of the program. Third, we select a sample using convenience sampling that would introduce selection bias.

\section{Conclusion}

This study found that blended learning could reduce the HIV-related stigma and discrimination from nurses. This underscores the utility of this intervention to change the perceived of stigma and discrimination of health workers, as well as potential to generalize or adapt this intervention to other settings in the region and beyond. Future study using rigor method is needed to confirm this finding.

\section{References}

Bandura, A. (1994). Social cognitive theory and exercise of control over HIV infection. In Preventing AIDS, pp. 25-59.

Bandura, A., \& Walters, R. H. (1977). Social learning theory (Vol. 1). Prentice-hall Englewood Cliffs.

Banteyerga, H., Kidanu, A., Abebe, F., Alemayehu, M., Fiseha, B., Asazenew, A., Ruden, C., Asfaw, Y., \& Shibru, A. (2005). Perceived stigmatization and discrimination by health care providers toward persons with HIV/AIDS. Miz-Hasab Research Center, Addis Ababa, IntraHealth International. http://dx.doi.org/10.13140/2.1.3556.7687

Batson, C. D., Lishner, D. A., Carpenter, A., Dulin, L., Harjusola-Webb, S., Stocks, E. L., Gale, S., Hassan, O., \& Sampat, B. (2003). "As you would have them do unto you": Does imagining yourself in the other's place stimulate moral action?, Personality and SocialPsychologyBulletin, 29(9), 1190-1201. https://doi.org/10.1177/0146167203254600

Chan, B. T., \& Tsai, A. C. (2017). Personal contact with HIV-positive persons is associated with reduced HIV-related stigma: Cross-sectional analysis of general population surveys from 26 countries in subSaharan Africa. Journal of the International 
Heni Purnama: Effectiveness Blended Learning in Reducing HIV-Related Stigma and Discrimination

AIDS Society, 20 (1), 1-8. https://dx.doi. org/10.7448\%2FIAS.20.1.21395

Corrigan, P. W., Morris, S. B., Michaels, P. J., Rafacz, J. D., \& Rüsch, N. (2012). Challenging the public stigma of mental illness: a meta-analysis of outcome studies. Psychiatric Services, 63(10), 963-973. https://doi.org/10.1176/appi.ps.201100529

Dlamini, P. S., Wantland, D., Makoae, L. N., Chirwa, M., Kohi, T. W., Greeff, M., Naidoo, J., Mullan, J., Uys, L. R., \& Holzemer, W. L. (2009). HIV stigma and missed medications in HIV-positive people in five African countries. AIDS Patient Care and STDs, 23(5), 377-387. https://dx.doi. org/10.1089\%2Fapc. 2008.0164

ErvingGoffman, S. (1963). Notes on the management of spoiled identity. Englewood Cliffs, NJ: Pren-tice-Hall.Ezedinachi, E. N. U., Ross, M. W., Meremiku, M., Essien, E. J., Edem, C. B., Ekure, E., \& Ita, O. (2002). The impact of an intervention to change health workers' HIV/AIDS attitudes and knowledge in Nigeria: a controlled trial. Public Health, 116(2), 106-112.

Feyissa, G. T., Abebe, L., Girma, E., \& Woldie, M. (2012). Stigma and discrimination against people living with HIV by healthcare providers, Southwest Ethiopia. BMC Public Health, 12(1), 522.

https://doi.org/10.1186/1471-2458-12-522

Kinsler, J. J., Wong, M. D., Sayles, J. N., Davis, C., \& Cunningham, W. E. (2007). The effect of perceived stigma from a health care provider on access to care among a low-income HIV-positive population. AIDS Patient Care and STDs, 21(8), 584-592. https://doi.org/10.1089/apc.2006.0202

Kurien, M., Thomas, K., Ahuja, R. C., Patel, A., Shyla, P. R., Wig, N., Mangalani, M., Kasthuri, A., Vyas, B., \& Brogen, A. (2007). Screening for HIV infection by health professionals in India. The National Medical Journal of India, 20(2), 59-66.

Li, L., Wu, Z., Liang, L.-J., Lin, C., Guan, J., Jia, M., Rou, K., \& Yan, Z. (2013).
Reducing HIV-related stigma in health care settings: a randomized controlled trial in China. American Journal of Public Health, 103(2), 286-292. https://dx.doi. org/10.2105\%2FAJPH.2012.300854

Lindayani, L and Maryam, N.N.A. (2017). Tinjauan sistematis: Efektifitas palliative home care untuk pasien dengan HIV/AIDS. (Systematic review: The effectiveness of alliative home care for patients with HIV / AIDS). Jurnal Keperawatan Padjadjaran, 5 (1), 29-36. https://doi.org/10.24198/jkp. v5i1.347

Lindayani, L., Ibrahim, K., Wang, J.-D., \& Ko, N.-Y. (2017). Independent and synergistic effects of self- and public stigmas on quality of life of HIV-infected persons. AIDS Care, 30(6), 706-713. https://doi.org/0.1080/09540 121.2017.1396282

Manganye, B. S., Maluleke, T. X., \& Lebese, R. T. (2013). Professional nurses' views regarding stigma and discrimination in the care of HIV and AIDS patients in rural hospitals of the Limpopo province, South Africa. African Journal of AIDS Research, 12(1), 33-40. https://doi.org/10.2989/16085 906.2013 .815411

McKeever, R. (2015). Vicarious experience: Experimentally testing the effects of empathy for media characters with severe depression and the intervening role of perceived similarity. Health Communication, 30(11), 1122-1134. https://doi.org/10.1080/1041023 6.2014 .921969

Musheke, M., Ntalasha, H., Gari, S., McKenzie, O., Bond, V., Martin-Hilber, A., \& Merten, S. (2013). A systematic review of qualitative findings on factors enabling and deterring uptake of HIV testing in SubSaharan Africa. BMC Public Health, 13, 220. https://doi.org/10.1186/1471-2458-13-220

Nyblade, L., Stangl, A., Weiss, E., \& Ashburn, K. (2009). Combating HIV stigma in health care settings: what works? Journal of the International AIDS Society, 12(1), 15. https:// dx.doi.org/10.1186\%2F1758-2652-12-15 
Heni Purnama: Effectiveness Blended Learning in Reducing HIV-Related Stigma and Discrimination

Pettigrew, T. F., \& Tropp, L. R. (2006). A meta-analytic test of intergroup contact theory. Journal of Personality and Social Psychology, 90(5), 751-783. https://doi. org/10.1037/0022-3514.90.5.751

Pisal, H., Sutar, S., Sastry, J., KapadiaKundu, N., Joshi, A., Joshi, M., Leslie, J., Scotti, L., Bharucha, K., \& Suryavanshi, N. (2007). Nurses' health education program in India increases HIV knowledge and reduces fear. Journal of the Association of Nurses in AIDS Care, 18(6), 32-43. https://doi. org/10.1016/j.jana.2007.06.002

Rahmati-Najarkolaei, F., Niknami, S., Aminshokravi, F., Bazargan, M., Ahmadi, F., Hadjizadeh, E., \& Tavafian, S. S. (2010). Experiences of stigma in healthcare settings among adults living with HIV in the Islamic Republic of Iran. Journal of the International AIDS Society, 13(1), 1-11. https://dx.doi. org/10.1186\%2F1758-2652-13-27

Shen, M.J. and Wellman, J.D. (2018). Evidence of palliative care stigma: The role of negative stereotypes in preventing willingness to use palliative care. Cambridge University Press, 17(4). https://doi. org/10.1017/s1478951518000834
Steward, W. T., Bharat, S., Ramakrishna, J., Heylen, E., \& Ekstrand, M. L. (2013). Stigma is associated with delays in seeking care among HIV-infected people in India. Journal of the International Association of Providers of AIDS Care, 12(2), 103-109. https://doi. org/10.1177/1545109711432315

Sweeney, S. M., \& Vanable, P. A. (2016). The association of HIV-related stigma to HIV medication adherence: a systematic review and synthesis of the literature. AIDS and Behavior, 20(1), 29-50. https://doi. org/10.1007/s10461-015-1164-1

UNAIDS. (2016). No Title. UNAIDS. Retrieved March 14, 2020, from http://www. unaids.org/en/resources/

Yiu, J. W., Mak, W. W. S., Ho, W. S., \& Yu, Y. (2010). Social Science \& Medicine Effectiveness of a knowledge-contact program in improving nursing students' attitudes and emotional competence in serving people living with HIV/AIDS. Social Science \& Medicine, 71(1), 38-44. https:// doi.org/10.1016/j.socscimed.2010.02.045 